\title{
"Surm on ainus, mis hirmutab": viirusnakkushaiguste ja nendega seotud vaktsineerimise tähenduse loomine gripi ja koroonaviiruse näitel
}

\author{
Kadi Lubi \\ Tallinna Tervishoiu Kõrgkooli tervishariduse keskuse dotsent \\ kadi.lubi@ttk.ee \\ Eliisa Metsoja
}

Tallinna Tervishoiu Kõrgkooli bakalaureus, Terviseameti gripikeskuse

peaspetsialist

Eliisa.Metsoja@gmail.com

Kaie Eha

Tallinna Tervishoiu Kõrgkooli meditsiinitehnilise hariduse keskuse farmatseudi ingliskeelse õppekava juht

Kaie.Eha@ttk.ee

Silja Mets-Oja

Tallinna Tervishoiu Kõrgkooli tervishariduse keskuse juht Silja.Mets-Oja@ttk.ee

Lilian Ruuben

Tallinna Tervishoiu Kõrgkooli meditsiinitehnilise hariduse keskuse juht

Lilian.Ruuben@ttk.ee

Teesid: Vaatamata sellele, et vaktsineerimine on tõhus meede gripi ennetamiseks, on gripivastane vaktsineerimine olnud Eestis tagasihoidlik. 2019. aasta lõpul alguse saanud koroonaviiruse pandeemia on esile toonud vaktsineerimise kui tervishoiualase meetme olulisuse, kuid hiljutised uuringud viitavad, et ka koroonaviiruse vastane vaktsineerimine võib jääda oodatust kasinamaks, sest inimesed ei pruugi ennast vaktsineerida. Artiklis mõtestame üheksa poolstruktureeritud intervjuu andmetele tuginedes võimalikke viise, kuidas luuakse vaktsineerimise kohta tähendusi ning miks ja kuidas mõjutavad need vaktsineerimisotsuse kujunemist hooajalise ja pandeemilise viirusnakkushaiguse puhul.

Märksõnad: gripp, haiguse tähenduse loomine, koroonaviirus (COVID-19), vaktsiinides kahtlemine, vaktsineerimine 


\section{Sissejuhatus}

Hooajaline gripp ei põhjusta noortele ja tervetele inimestele küll suuri tervisekahjusid, kuid sel haigusel on arvestatavad tervise-, ühiskondlikud ja majanduslikud mõjud, eriti riskirühmade seas (Govaert \& van Essen 2003), põhjustades igal aastal üle maailma epideemiaid (Petrova \& Russell 2018), haigestumust ja suremust (Rossman \& Lamb 2011). Seejuures võivad gripi tüsistused olla tõsised (nt müokardi infarkt, bakteriaalne kopsupõletik, neerupuudulikkus) ning lõpliku paranemiseni võib kuluda nädalaid (Govaert \& van Essen 2003: 1266; Jorgensen et al. 2018). 2018/19. gripihooajal oli Eestis hinnanguliselt 45-55 tuhat gripijuhtumit, hospitaliseeriti 1662 ja suri 57 inimest (Terviseamet 2019).

Kuigi gripivastane vaktsineerimine on haiguse ennetamisel esmane (Petrova \& Russell 2018) ja tõhusaim vahend, on gripivastase immuniseerimise määr pigem madal. Gripihooajal 2014/15 suutis vaid Ühendkuningriik ainsa Euroopa riigina vaktsineerida $75 \%$ vanemaealistest (teiste riskirühmade hõlmatus jäi alla 40\%) (Jorgensen et al. 2018). Eestis vaktsineeriti 2019. aastal kogu rahvastikust $10 \%$ (vanemaealistest 15\%) (joonis 1), mis on kaugel soovituslikust $75 \%$ (WHO 2020b) ja teistes Euroopa riikides saavutatud hõlmatusest (Robert et al. 2019).

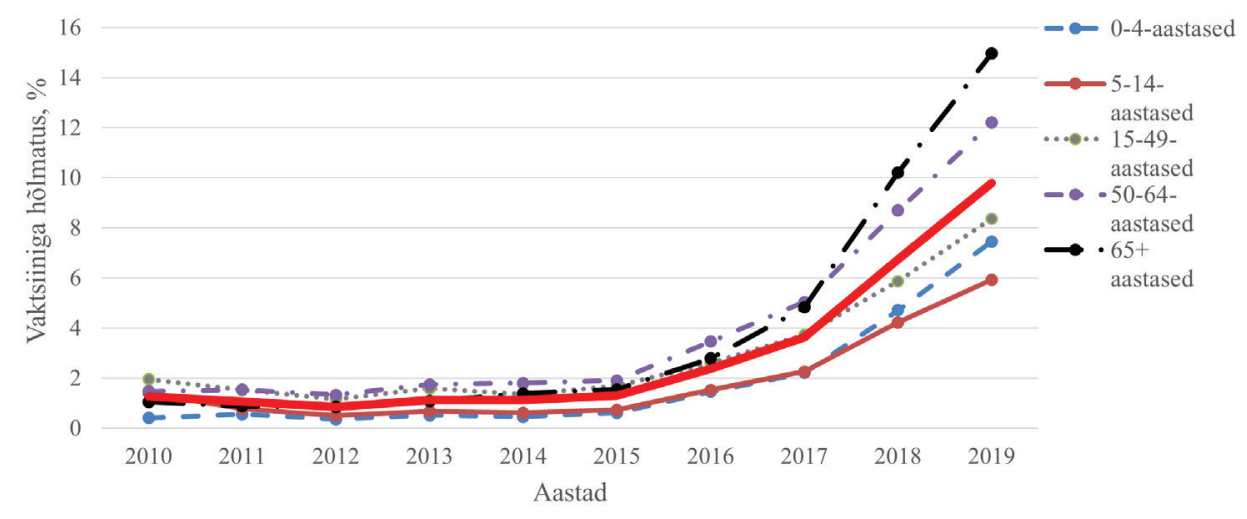

Joonis 1. Gripivastase vaktsineerimise hõlmatus erinevate vanusegruppide lõikes 2010-2019. Tervise Arengu Instituut 2020. 
Koroonatõbi on viirusnakkushaigus, mis põhjustab haigestunutele kergeid kuni mõõduka tugevusega respiratoorseid sümptomeid, millest enamik inimesi paraneb sümptomaatilise raviga, kuid vanemaealistel ja erinevate terviseprobleemidega riskirühmade esindajatel võib ka välja kujuneda raske haigus, mis võib lõppeda surmaga (WHO 2020a). Koroonaviiruse (COVID-19) pandeemia kuulutati välja 11. märtsil 2020 (WHO 2020c), sellele järgnes 12. märtsil eriolukorra väljakuulutamine Eestis (EVV 2020). Euroopa Liidus, sh Eestis algas prioriteetsete sihtrühmade vaktsineerimine 27. detsembril 2020, kuid uuringutes on juba leitud, et inimesed, kes ei tunne ennast COVID-19 poolt ohustatuna, kahtlevad rohkem enda vaktsineerida laskmises võrreldes riskirühmade liikmetega, kes end otseselt ohustatuna tunnevad (Dror et al. 2020). 2020. aasta 31. detsembri seisuga oli Eesti diagnoositud 28409 koroonaviiruse haigusjuhtu ja 234 surma (OKE 2021).

Käesolev artikkel võtab vaatluse alla end gripi vastu mittevaktsineerinud (samas mitte vaktsiinivastaste) inimeste uskumused ja arvamused gripi, koroonaviiruse (COVID-19) ja nendega seotud vaktsineerimise osas. Tuginedes üheksale poolstruktureeritud intervjuule küsime, kuidas loovad enda jaoks eelnevalt nimetatud haiguste vastase vaktsineerimise tähendust inimesed, kes vaktsineerimist üldiselt ebavajalikuks ei pea. Analüüsis oleme tuginenud sotsiaalkonstruktivistlikele lähenemistele (Conrad \& Barker 2010), mille kohaselt toimub haiguse ja tervisega seotud tähenduste konstrueerimine kultuurilisel tasandil, isiklikel kogemustel põhineval indiviiditasandil ja kolmandate osapooltega seotud tasandil. Varasemad uuringud maailmas on käsitlenud haiguse tähenduste konstrueerimist peamiselt krooniliste haiguste (nt Charmaz 2006; Morden \& Jinks \& Ong 2017) ja vähktõve (nt Buonaccorso et al. 2019) kontekstis. Samuti on uuritud vanemate vaktsineerimises kahtlemise ja vaktsiinivastasuse teket laste vaktsineerimise osas (nt Dubé \& Gagnon et al. 2014; Dubé \& Vivion et al. 2014; Sobo 2016), kuid hooajaliste viirusinfektsioonide ja käesoleva koroonaviiruse pandeemia ning viirusnakkushaigustega seotud vaktsineerimiste kontekstis seda seni tehtud ei ole, mistõttu võimaldavad tulemused saada esmast tagasisidet selle osas, kuidas luuakse nimetatud juhtudel viirusnakkushaiguse ja sellega seotud vaktsineerimise tähendust. Viirusnakkushaiguste alase tähendusloome (st selle, mida see haigus meie ühiskonnas kultuuriliselt ja ühiskondlikult tähendab) uurimine võib anda olulist informatsiooni selle kohta, miks inimesed viirusnakkushaiguste (nagu gripp ja koroonatõbi) vastase vaktsineerimise osas kõhklevad või seda isegi väldivad. See teadmine võib aga aidata edasises selgitustöös (nii rahvateavituse kui ka pikemaajalise haridustegevuse kontekstis), samuti selgitada meditsiiniantropoloogia ja -sotsioloogia potentsiaali haiguste ja laiemalt terviskäitumise mõtestamisel, toetamisel ja suunamisel. 


\section{Haiguse tähenduse konstrueerimine}

Lääne meditsiinis valitsev haigusi käsitlev biomeditsiiniline mudel (Nettleton 2013: 2) kirjeldab haiguseid kui patofüsioloogilisi protsesse. Selline lähenemine ei võimalda aga hinnata haiguse mõju inimese elu teistele valdkondadele peale kehalise/füüsilise. Vastandina biomeditsiinilisele mudelile võimaldab sotsiaalkonstruktivism tuua esile kultuuriliste ja ühiskondlike süsteemide mõju haiguse tähendusele ja kogemusele (Conrad \& Barker 2010). Seetõttu kasutatakse meditsiinisotsioloogias inglise keeles haiguse kohta kaht sõna, eristamaks haiguse kliinilist ja sotsiaalset kulgu ja mõju: disease tähistab düsfunktsionaalset keha ja illness tähistab katkestuste kogemust (experiences of discontinuities) igapäevategevuste sooritamisel (Eisenberg 1977). Kuigi lähenemist on kritiseeritud, võimaldab see siiski analüüsida ja mõista haigusega kaasnevaid muid mõjusid peale kehaliste. Samas ei tähenda see ainult ühe inimese eluilma (life-world) kontekstis esinevaid haigusega seotud kogemusi, vaid sümptomeid tõlgendatakse ka muude iseloomulike eluilmade kontekstis, mille kujunemist mõjutavad sotsiaaldemograafilised ja -kultuurilised tegurid nagu näiteks ühiskondlik klass, etnilis-kultuuriline päritolu, vanus ja sugu (Toombs 1992: 37). Kathy Charmaz (2006) on krooniliste haiguste näitel välja toonud, et tähendusi luuakse kollektiivselt, kuid neid tõlgendatakse individuaalselt. Indiviiditasand oma praktiliste nüansside ja harjumuslike käitumisviisidega võib samuti mõjutada viisi, kuidas inimesed omandavad ja/või kokku lepivad kroonilise haigusega seotud uusi praktikaid (Charmaz 2006; Lubi 2019). Haiguse tähenduse loomise aspektidena on ka välja toodud rahvatarkust, bio- ja alternatiivmeditsiinist tulenevat ekspertteadmist ning massimeediast ja internetist saadud informatsiooni (Lupton 2012: 86).

Peter Conrad ja Kristin K. Baker (2010) on kokku võtnud haiguste tähenduste sotsiaalkonstruktivistliku uurimise ning toonud välja kolm peamist lähenemist - kultuurilise, indiviidikeskse ja kolmandatest osapooltest lähtuva. Haiguste kultuurilise tähenduse loomisel ei ole fookuses niivõrd haiguse olemus kuivõrd ühiskonna reaktsioon ja suhtumine haigesse inimesesse ja haiguskogemusse tervikuna. Indiviidikeskse lähenemise korral on fookuses üksikisiku kogemuslik tasand ja tema arusaamad haigusest. Kolmandate osapooltega (nt erinevad arvamusliidrid, meedia jne) seotud lähenemise korral on haiguse tähenduse loomise keskmes huvitatud osapooled, kusjuures meditsiinilised teadmised haiguse kohta pole tingimata objektiivsed, mis toob eriti selgelt esile selle, et haigused (nii füüsilises kui ka sotsiaalses mõttes) on sama palju sotsiaalsed kui meditsiinilis-teaduslikud (Conrad \& Barker 2010). 


\section{Vaktsiinis kahtleja, vaktsiinieitaja, vaktsiinivastane ${ }^{1}$ - kes nad on?}

Samaaegselt neoliberaalse individuaalse vastutuse tõusuga (Dutta 2015) on esile kerkinud vaktsiinide kasulikkuses kahtlejaid. Kultuurilist nähtust, kus eeskujuks on individuaalset vastutust võttev ettevõtlik ja iseseisev tervisekäituja, nimetatakse "tervisepüüdluseks või tervisetaotluseks" (healthism, mõiste võetud kasutusele varem Eestis läbi viidud uuringu soovituse järgi, kuigi autorid tunnistavad, et ingliskeelsele mõistele seni üldtunnustatud eestikeelne vaste puudub (Uibu \& Vihalemm 2017)), mis vaktsineerimise kontekstis avaldub eeskätt vanemate kahtlustes oma laste vaktsineerimise osas (Peretti-Watel et al. 2015). Vaktsiinides kahtlemine toob kaasa selle, et immuniseeritakse vähem inimesi kui kättesaadav teave ja teenused seda võimaldaksid (Dubé \& Gagnon et al. 2014). COVID-19 pandeemia kontekstis on juba arutletud selle üle, kas see suudab lahendada üldisema vaktsiinides kahtlemise probleemi, kuid leitud, et isegi kui see lahendab probleemi COVID-19 puhul, ei pruugi vaktsiinivajadusega seotud arusaam laieneda teiste haiguste vastasele vaktsineerimisele (Harrison \& Wu 2020).

Kõige tavapärasemalt nimetatakse nähtust vaktsiinivastasuseks, kuid tegelikkuses on olukord mitmetahulisem ja nii on leitud ka, et need, kes vaktsiinides kahtlevad, saab vaktsineerimisega seotud käitumise põhjal jagada kolme rühma (Hagood \& Herlihy 2013). Kõige tavapärasema arusaama järgi saaks eristada vaktsiinide vastaseid (vaccine rejector), eelkõige lapsevanemaid, kes on seisukohal, et vaktsiinid teevad rohkem halba kui head või on osaks valitsuste, tervishoiuorganisatsioonide ja ravimifirmade vandenõust. Allison Hagoodi ja Stacy Mintzer Herlihy (2013) tüpoloogia põhjal on selle rühma liikmetele omistatud ka teistest sagedasem täiend- ja alternatiivmeditsiini praktiseerimine. Teise rühma moodustavad vaktsiinide eitajad (vaccine resistant), kes on küll vaktsineerimisele vastu, kuid on valmis kaaluma vaktsineerimise tõhususe ja ohutusega seotud informatsiooni. Kolmanda rühma moodustavad vaktsiinides kahtlejad (vaccine hesitancy), kellel ei ole konkreetset vastuseisu vaktsiinide osas, kuid kes võivad last vaktsineerima tulles ilmutada teatud ärevust, kahevahelolekut ning kui nad ka lasevad last vaktsineerida, siis teevad seda vastumeelselt (Hagood \& Herlihy 2013).

Varasemates uuringutes on välja toodud erinevaid barjääre, mis mõjutavad gripivastase vaktsineerimise vähest hõlmatust (Schmid et al. 2017). Nii on välja toodud psühholoogilised barjäärid (nt väiksem tajutud risk gripi tagajärgede osas, vähene surve olulistelt teistelt, puuduv minevikukogemus, kasinad teadmised gripi ja vaktsineerimise osas jne), füüsilised barjäärid (nt ebatervislik 
elustiil või puuduv meditsiiniline seisund), kontekstist tulenevad barjäärid (nt vaktsineerimise kättesaadavus, vähene suhtlus tervishoiusüsteemi erinevate osadega) ja sotsiaaldemograafilised barjäärid (nt eakus) (Schmid et al. 2017). Lisaks on uuringutes ka näidatud, et nakkushaiguste alane vähene teadlikkus ei pruugi puudutada ainult laiemat avalikkust, vaid ka tervishoiutöötajaid (Hall \& Wolf 2019). Hiljutises COVID-19 vaktsiini puudutavas uuringus on leitud, et tervishoiutöötajad, kes ei puutu koroonatõve patsientidega otseselt kokku, usaldavad COVID-19 vaktsiini vähem kui rahvastik üldiselt (Dror et al. 2020).

Seega on igasugune vaktsiinidest hoidumine kompleksne nähtus, mis eksisteerib kogu maailmas ning millega tegelemisel ei ole võimalik välja pakkuda üht toimivat meetodit (Schuster et al. 2015). Pigem tuleks vaktsiinialase harimise ja poliitika puhul segmenteerida sihtrühmad ja läheneda igale rühmale viisil, mis neid parimal moel kõnetaks (Hagood \& Herlihy 2013), sest vastuseisu vaktsiinidele saab käsitleda otsustusprotsessina, mis sõltub inimeste usaldusest tervishoiuasutuste ja peavoolu meditsiini suhtes (Peretti-Watel et al. 2015).

\section{Analüüs}

Andmete kogumiseks viisime läbi üheksa poolstruktureeritud intervjuud. Intervjuude suhteliselt väike arv võib olla uuringu miinuseks, kuid et eesmärk oli saada esmast teavet teema käsitlemiseks ning uurijate konsensuslikul hinnangul saavutati andmete küllastus (data saturation), siis antud uuringu kontekstis oli osalejate arv piisav. Valimi moodustamiseks kasutasime kombinatsiooni mugavus- ja lumepallivalimist. Uuringusse kaasamise kriteeriumiteks olid osaleja vanus (alates 18. eluaastast), asjaolu, et viimase kahe aasta jooksul polnud osaleja gripi vastu vaktsineeritud ning see, et tegemist polnud põhimõttelise vaktsiinivastasega. Intervjuud toimusid veebruarist juunini 2020 ning kuna sellesse perioodi jäi ka riigis väljakuulutatud eriolukord, toimus enamik intervjuudest elektrooniliste kanalite (Facebook, Messenger, Skype, mobiiltelefon) vahendusel, mida saab pidada üheks uuringu puuduseks, mis vähendas võimalust märgata ja arvesse võtta vestluste mitteverbaalseid nüansse (täpsemalt on uuringu piirangud välja toodud vastavas alapeatükis). Intervjuud kestsid keskmiselt 40 minutit. Uuringule ei taotletud eetikakomitee luba. Konsulteerisime Tallinna Meditsiiniuuringute Eetikakomiteega ning suhtluse tulemusel leidsime, et luba ei ole vajalik, kuna uuriti nähtust (vastavasisuline suhtlus 2018. aasta oktoobris) ning osalejate tervise- ega isikuandmeid ei kogutud ega säilitatud. Sellele vaatamata järgisime uuringu läbiviimisel meditsiinieetika (Beauchamp 2015), Helsingi deklaratsiooni (World Medical Association 2013) ja 
isikuandmete kaitse seaduse (RT 2019) põhimõtteid. Kõik salvestised transkribeerisime vastavalt suulise kõne metoodikale (Hennoste 2000) ning kustutasime seejärel. Transkriptsioonid kodeerisime ning kood sisaldas uuringukoodi (flu), osaleja järjekorranumbrit ja vanust. Kokku osales uuringus Eestis elavad seitse naist ja kaks meest vanuses 27-70. Intervjuutekstide analüüsi viisime läbi, lähtudes haiguste konstrueerimise kultuurilisest, üksikisiku ja kolmandate osapoolte tasandist. Analüüsisime seda, kuidas mõtestatakse enda jaoks haiguste (gripp ja COVID-19) olemust, neist tulenevaid ohte ja võimalikke riske ning seeläbi ka seda, kuidas on enda jaoks konstrueeritud arusaamad nende haiguste ja vaktsineerimise kohta.

\section{Tähenduse loomine kultuurilisel tasandil}

Kultuurilise tasandi roll on haiguste tähenduste konstrueerimisel sageli seotud sellega, milline tähendus on haigusele ühiskonnas antud, kuigi haiguses endas pole midagi stigmatiseerivat (nt vaimse tervise häired, seksuaalsel teel levivad haigused, vähk jne) (Conrad \& Barker 2010). Gripi puhul väljendus kultuurilise tasandi tähendusloome osalejate vastustes seeläbi, et ühiskondlikult ei peeta grippi ohtlikuks viirusnakkushaiguseks:

Peaks rääkima meedias ja rohkem sellest, et tegelikult gripp on ka ohtlik. Kuidagi on jäänud inimestel see tunne, et see pole ohtlik. Tegelikult ei räägitud, et gripp lõpeb ka surmaga, [---] et gripp on ohtlik. Nad võtsid, et gripp on paratamatus [---] (6flu_F68).

Nagu tsitaadist nähtub, peetakse uuringus osalejate hinnangul grippi kui viirusnakkushaigust pigem paratamatuseks, mis põhjamaise kliima ja elukorraldusega kaasas käib ning mis seetõttu on tekitanud väärtõlgendusliku lisatähenduse, et tegemist pole ohtliku haigusega. Peter Conrad ja Kristin K. Baker (2010) on välja toonud, et teatud haiguste puhul lahkneb haiguse kultuuriline tähendus bioloogilisest ja eelnevalt toodud tsitaat ilmestab seda selgelt - kuigi bioloogiliselt nakkav ja riskirühmadele ka potentsiaalselt eluohtlik, on kultuuriline arusaam gripi olemuse kohta vastupidine. Oluline on siinjuures see, et vastajad tõid välja ka tervishoiutöötajate endi n-ö koroonaeelse käitumise, kus ilmselgete haigustunnustega arstid või õed tegelesid patsientidega, mis viitab, et tegemist ei olnud ainult meditsiinikaugete eestimaalaste võhikliku käitumisega gripi vm hooajaliste külmetushaiguste suhtes, selline käitumine on olnud valdav kultuuriline norm ning pigem on tekitanud küsimusi see, kui keegi kerge haigestumise korral tööle ei tule. Tuleb silmas pidada, et gripi- ja 
koroonaviiruse korral võib teatud osadest juhtudel rääkida kergematest sümptomitest ja enesetunne kui subjektiivselt tajutud sümptom võib olla see, mida kahtluse alla pannakse. Varasemas uuringus on näidatud, et meditsiiniliselt põhjendamata sümptomite korral võidakse patsienti pidada ka sotsiaalselt ja isiksuslikult problemaatiliseks, mistõttu toob haiguse diagnoos kaasa ka vältimatud kõrvaltoimed (Mik-Meyer \& Obling 2012). See asjaolu võib täiendavalt põlistada ühiskondlikult soositud arusaama, et külmetushaigus (mis siis, et bioloogiast lähtudes hoopis viirushaigus) ei anna õigust eemalduda sotsiaalsetest rollidest.

Analüüsil ilmnes, et kuna koroonaviiruse puhul pikaajalist ja ühiskondlikult või kultuuriliselt ühtset arusaama ei ole tekkinud, on koroonaviirusega seotud tähenduste tekkimisel oluline roll emotsionaalsetel tõlgendustel. Nagu üks vastaja välja tõi:

Koroonaga ehmatas ainult surm, ega muu ei ehmata. Kui ütled, et saad hingamispuuduse, see ei hirmuta, surm hirmutab (6flu_F68).

Lisaks surmahirmule toodi aga esile ka abstraktsemat hirmu tundmatuse ees:

Võib-olla lihtsalt see tundmatus või nagu teadmatus, ma ei tea, kas ta otseselt hirm on. Võib-olla on hirm lihtsalt selle teadmatuse ees, et mis ees võib oodata (4flu_F27).

Haiguste tähenduse kujunemine toimub nii biomeditsiinilisel (st sümptomid ja haiguse kliiniline pilt) kui kogemuslikul tasandil (Conrad \& Barker 2010) ning eespool esitatud tsitaadid toovad selle selgelt esile - kui tähenduse loomeks puudub piisav biomeditsiiniline informatsioon, luuakse tähendusi teistel tasanditel. Koroonaviiruse puhul on meditsiinilise tähenduse loome keerukus tulenenud haiguse levikust peale sellest, et tõenduspõhisel meditsiinil ei olnud piisavat infot haiguse olemuse, mõjude, tüsistuste jm oluliste tegurite osas. Ühtse meditsiinilise arusaama puudumine tõi kaasa emotsionaalsed (sh hirmul põhinevad) reageeringud tervishoiutöötajatel, mis kandusid ka teistesse sotsiaalsetesse rühmadesse.

Tulenevalt haigusega seotud tähenduse loomest kultuurilisel tasandil luuakse tähendus ka vaktsineerimise kohta:

Ei, ma ei ole kindlasti nagu selles mõttes gripivaktsiinivastane kohe, selles mõttes absoluutselt mitte, lihtsalt mina ei ole pidanud seda enda jaoks vajalikuks. Ja, ja võib-olla ma nopingi siis üles nagu selliseid lugusid, kus on nagu et vot, et nü̈̈d talle tehti gripivaktsiin ja vaata ta jäi veel raskemalt haigeks ja võib-olla nagu mina just nagu niimoodi alateadlikult nopin neid lugusid üles, et [---] Ega seda ei tule ju keegi rääkima ka, et 
ma vaktsineerisin ennast gripi vastu ja [---] ei jää haigeks. Aga noh, nad ei tule seda ju ka sulle rääkima (2flu_F51).

Ülaltoodud tsitaat toob välja paar olulist nüanssi - esmalt selle, et hooajalise gripiga seotud vaktsineerimine või mittevaktsineerimine ei pruugi olla seotud üldisema vaktsiinivastasusega. Saadud tulemust kinnitab Hagoodi ja Herlihy (2013) pakutud käsitlus, mille kohaselt pole vaktsiinivastasus käsitatav üheselt, sellel on erinevaid tahke, mistõttu on ka probleemi endaga tegelemine, nt tervisekommunikatsiooni seisukohalt pigem keeruline kui lihtne. Ka siinsete tulemuste põhjal ei saa väita, nagu aitaks gripivaktsiinist loobujaid veenda vastav ühesuunaline teavitustöö, pigem peaks see olema nüansseeritum ja fokuseeritum. Samuti toob antud näide esile selle, et kultuurilise tasandi tähendusloome sõltub ka "rahvalugudest" ning nende toonist, mida on nt Deborah Lupton (2012) ka varem välja toonud. Teisisõnu: kui positiivne tulemus on normaalsus, millest ei räägita, aga negatiivne tulemus saab tähelepanu, jääb kõlama viimane, mis hakkab ka vaktsineerimisotsust mõjutama.

Koroonaviiruse 2020. aasta kevadises pandeemias nähti õppetundi, mis meenutas inimestele põhilisi hügieenitõdesid:

Ma loodan väga, et inimesed õppisid, ütleks sellest epideemiast... on ju, et enam ei roni sulle kaubanduskeskuses äkki nii väga keegi sulle selga on ju [---] või tugevdaks oma immuunsüsteemi kuidagiviisi kuidagi [---] mina arvan küll, et gripihooajal ka tegelikult jah, et inimesed täiesti võiksid ju kaubanduskeskusesse maskiga [---] et ta ei ole, eks ole, noh, et küll ka kõige [---] sada protsenti, tõhus meetod, meede on ju, aga et võib olla abiks ikka (7flu_F49).

Vajaduse hoida teiste inimestega füüsilist vahemaad tõi mitu osalejat välja kui uue reaalsuse. Haigusest ja selle piirangutest lähtuv kohustus hoida vahemaad on kindlasti aspekt, mis vajab täiendavat uurimist, eriti Eesti ühiskonna erinevates rahvusrühmades.

Eesti ühiskonnas on olnud keeruline tõkestada haigete inimeste ringiliikumist, sest kultuuriliselt omase lähenemise kohaselt pole gripp ega selle sümptomitega sarnane koroonaviirus tõsised haigused. Sellele lisanduvad võimalik sotsiaalne stigmatiseerimine, mis lähtub kahtlusest, et tegelikkuses ei olegi inimene haige, aga ka võimalik tervishoiukorraldus, mille kohaselt kaotab haigestunu haigushüvitise korralduse tõttu osa oma sissetulekust. 


\section{Tähenduse loomine üksikisiku tasandil}

Indiviidi tasandil luuakse haiguse tähendus vastavalt isiklikele kogemustele gripi ja sellega seotud vaktsineerimise osas. Isiklikud kogemused võivad olla negatiivsed või neutraalsed, mis tähendab, et vaktsineerimise järel tunti kas negatiivseid kõrvalmõjusid või ei tuntud erinevust võrreldes mittevaktsineerimisega:

Mul on olnud üks halb kogemus, et kus, kus nagu tööandja finantseeris seda, et ma saaks ennast nagu vaktsineerida, siis ma mõtlesin, et ma kasutan seda juhust ja, ja olin kordades rohkem haige kui, kui, siis kui, kui ma ei vaktsineerinud ennast. Ja, ja see noh, minu muidugi loomulikult stressitase oli natuke kõrgem tollel hetkel, mis tegelikult ikkagi nagu nagu seda justkui nagu reklaamitakse, et, et hoolimata sellest, et sa ei pea oma elustiili muutma, aga kui sa ennast vaktsineerid, siis oled kogu aeg terve, aga tegelikult minu puhul see nagu ei [---] toiminud. Sest et nagu mu stressitase on nagu noh varieerunud ja noh, ikkagi teed ju päevatööd ja ja toimetad ja vahet pole nagu, pigem ma olen tervem siis, kui ma ei vaktsineeri ennast võrdluses siis kui ma nagu olen vaktsineerinud (3flu_F27).

Tsitaat toob välja paar huvitavat aspekti. Esmalt see, et üks negatiivne kogemus võib avaldada mõju, mis kinnistab edasised samasisulised otsused või tervisega seotud käitumise. Teisalt aga see, et kuigi osaleja ise ka tunnistab oma tollast kõrgemat stressitaset, mis võis olla ka edasise haigestumise põhjus (või ka võimenduda vaktsiini toimel), tühistab vastaja samal ajal selle mõju siiski olematuks, andes vaktsiinile superjõu, mis peaks kõiki edasisi haigestumisi vältima. Samamoodi tõid vastajad välja erinevad (spetsiifilised/kroonilised) haigused, mis võivad olla vaktsineerimise vastunäidustuseks, kuid vaktsineerimisest keeldumise puhul laiendati vastunäidustust kõigile haigustele/haigestumistele.

Indiviidi tasandil on vaktsineerimise tähenduse mõtestamises oluline osa ka sellel, kas ennast nähakse riskirühma kuuluvana või ei. Vastanute põhjendused riskirühmade vaktsineerimise vajalikkuse osas olid vastuolulised. Nooremad osalejad leidsid, et nad ei pea ennast gripi vastu vaktsineerima, sest nad ei kuulu riskirühma, eakamad osalejad leidsid küll, et nad kuuluvad vanuse (ja ehk ka kaasuvate haiguste) tõttu gripi riskirühma, kuid põhjendusena, miks nad ennast vaktsineerima ei pea, toodi välja, et see pole vajalik, kuna koduse elustiili tõttu on võimalik haigestumist ennetada:

Ma olen kahevahel kogu aeg, olen ju riskirühm, üle 65, astmaatik [---] aga kuna ma kodus ei puutu [inimestega kokku] ja saan elu sättida, et ei 
pea minema kõige suuremal perioodil... väldin kinno minekut, saan elu reguleerida, aga inimesed, kes ei saa reguleerida, peavad vaktsineerima, õpetajad, tervishoiutöötajad, hooldustöötajad. Et saan ära hoida [haigestumist, grippi], mis ma oma immuunsüsteemi koorman... (6flu_F68).

Tsitaadist ilmneb kaks olulist aspekti - ühelt poolt arusaam, et gripp on välditav õige tegevusega ning teisalt arusaam, et vaktsineerimine on immuunsüsteemile (täiendav ja ebavajalik) koormus, mitte aga haigust ennetav meede. Need kaks arusaama võivad viidata vähestele teadmistele gripist ja sellega seotud vaktsineerimisest. Samas toob see välja täiendava tahu, kuidas kujunevad inimeste tervisega seotud käitumisviisid. Varasemalt omandatud tervisekäitumise harjumused võivad olulisel määral mõjutada hilisemate tervisega seotud otsuste ja käitumiste kujunemist või seda, kuidas (st millistele põhjustele tuginedes) neid muudetakse (Lubi et al. 2020). Siinkohal saab viidata ka eelnevalt välja toodud kultuurilise tasandi mõjule vaktsineerimisotsuse ja käitumise kujunemisel, mis on kooskõlas järeldusega, et tähendusi luuakse kollektiivselt, kuid nende tõlgendamine toimub individuaalselt (Charmaz 2006). Strateegiat, millele tuginedes põhjendada vaktsineerimisest loobumist, mõjutab ka kultuuriliselt kujunenud arusaam nn külmetushaiguste ennetamisest:

Siis siis jah nagu, kui, kui ei ole seda nagu suutlikkust, siis, siis loomulikult nagu kõik tavainimesed kes, kes nagu töötavad või õpivad, peaks nagu siis sellisel juhul nagu vaktsineerima, kui nad just ei ole nagu endale mingisugust nagu strateegiat välja mõelnud, et ma ei tea, iga septembrist alates kuni kuni siis märtsini ma söön kü̈̈slauku ja joon ingveriteed näiteks (3flu_F27).

Ingver on Eestis ravimtaimena ja külmetushaiguste ennetaja-tõrjujana küll üsna uus nähtus, kuid seda, et tõhusad ja käepärased vahendid on rahvameditsiinis olemas, on kultuuriliselt juurdunud teadmine, mida indiviidi tasandil taastoodetakse. Etnomeditsiin on kõikvõimas ja toimeid omistatakse taimedele ka siis, kui need teaduslikult ei pruugigi kinnitatud olla (Raal \& Arak 2006).

Mitmed osalejad toonitasid, et nende arusaamad gripivastase vaktsineerimise osas on kujunenud ka kättesaadava informatsiooni põhjal, mis ei toeta ootust, et vaktsiin on täielikult tõhus:

Samas mul ei ole seda täit usku, et ta ei jää grippi, saad aru, mis ma mõtlen, sellepärast et nad teevad selle mingi noh, mingi ühe [---] tüve vastu ja et siis mul nagu seda sada protsenti seda garantiid ei ole [---] ma ei ole sada protsenti kindel, et, et see annab selle garantii (5flu_F40). 
Nagu kaks viimast tsitaati välja toovad, võivad inimesed gripi vastu vaktsineerimise puhul tunda hirmu, kuidas võib väline tegur mõjutada immuunsüsteemi ning kuidas keha sellele mõjutusele reageerib. Samas on võimalik, et vastajad konstrueerivad vaktsineerimisele tõhususe ja ohutusega seotud tähendused üksnes selleks, et iseenda silmis õigustust otsida.

Koroonaviiruse kontekstis tõid osalejad esile ennetuse muutunud tähenduse. Huvitav oli see, et valmisolek ennast koroonaviiruse vastu vaktsineerida oli suurem nendel vastajatel, kellega toimusid intervjuud koroonaviiruse pandeemia esimese laine kõrghetkel (2020. aasta aprillis), kuigi ka siis mainis seda võimalust vaid paar osalejat. Seetõttu ei saa käesoleva uuringu tulemustele tuginedes väita, et koroonaviirus ja sellega seotud pandeemia oleksid mõjutanud märkimisväärselt valmisolekut viiruse vastu vaktsineerida. Ka Turu-uuringute AS poolt 2020. aasta augustis läbi viidud küsitluse tulemusel oli valmis ennast vaktsineerida laskma ligi $60 \%$ uuringus osalenutest, samas kui $19 \%$ ei soovinud seda just tõhususes ja ohutuses kahtlemise tõttu teha ning $21 \%$ osalenutest puudus selge seisukoht vaktsineerimise osas (Turu-uuringute AS 2020).

Nagu eelnevalt välja toodud, on oluline roll individuaalse tasandi tähendusloome kujunemisel seotud varasemate harjumuste ja elustiiliga (Lubi 2019; Lubi et al. 2020; Charmaz 2006). Seetõttu ei nähtud enda ja teiste inimeste tervise kaitse meetmena niivõrd suurenenud valmisolekut vaktsineerida, kuivõrd rõhutada sobivaid hügieenivõtteid ja sotsiaalset distantseerumist:

Ei, ma ei usu, et nii ruttu tuleb vaktsiin [---] ma olen väga selle usku, et peab käsi puhastama ja pesema. Ma arvan, et ma olen võimeline $k a$ kandma maski, ma olen seda usku. ma väga usun, et hügieen hoiab [haigestumise] ära. Ma väga usun, et see hügieen aitab (6flu_F68).

Oluline on välja tuua, et see konkreetne intervjuu toimus kuu aega pärast pandeemiast põhjustatud eriolukorra lõppemist, mis viitab, et isegi kui inimestel kujunesid eriolukorra jooksul erinevad arusaamad ennetavate meetmete osas, kohandusid need pärast kriisiolukorra lõppu ning püsima jäid ainult need uskumused ja tähendused, mis haakusid varasemate või tavapäraste tähendustega. Nii nagu erinevad autorid (Charmaz 2002; Schatzki 2013) on varasemalt välja toonud, viitab see ajaolule, et olemasolevad harjumuslikud käitumisviisid ei muutu pikaajaliselt ka suurimas kriisiolukorras.

\section{Kolmandatest osapooltest lähtuv tähenduse loomine}

Gripiga seotud tähenduse loomise puhul saab kolmandate osapooltena välja tuua erinevat tüüpi meediakanaleid, kuid ka olulisi teisi, sh arvamusliidreid. 
Kuigi viimane on enam seotud juba mainitud kultuurilise tasandi tähendusloomega, saavad siin esile tulla isikud, kelle arvamusi ja seisukohti meedia suurel määral vahendab.

Kõige madalama efektiivsusega meediaga seotud tegevuseks peeti vaktsineerimisega seotud reklaame:

No ma arvan, et ikkagi noh, need reklaamid väga võib-olla ei toimi niimoodi, sest nad on.. see on ikkagi kommerts minu jaoks nagu täiesti selline nagu noh, kuidagi teistmoodi, aga kui keegi näiteks räägiks, teeks mingisuguse live-video näiteks või üldse salvestaks mingi video kuskile ja see läheks nagu Internetti üles, siis mulle nagu tundub, et seda on palju lihtsam hoomata, sest kui näiteks mina võtan kätte ja loen siis seda, mul palju raskem üldse nagu talletada või aru saada, kui see, kui keegi räägib. Minu, minul on niimoodi lihtsam ja ma arvan, et noh, minusuguseid on veel, kellel niimoodi oleks lihtsam. Et keegi seletab lahti, et ei ole need meditsiinilised terminid lihtsalt kuskil, vaid ongi nagu inimkeeles lahti seletatud, et lihtinimene ka saaks aru, kes ei ole antud erialal tööl (4flu_F27).

Ülaltoodud tsitaadi puhul on oluline, et kui reklaami peetakse vähetõhusaks võimaliku turundusliku sisu tõttu, siis internetist leitava vahendatud sisu osas nii kriitilist hinnangut ei anta ning seda peetakse isegi oluliseks infoallikaks, mis võib mõjutada vaktsineerimisega seotud otsust. Antud vastaja puhul tuleb tähele panna, et tegemist oli nooremapoolse vastajaga. Eakamad vastajad olid ka internetist leitava sisu suhtes kriitilisemad ning leidsid, et sugugi kõik internetis sisalduv ei peaks seal saadaval olema:

Praegu on ju nii palju, Facebook'i-taolist, seda meediat, kõik loevad, see ka aitab. Aga mitte ainult, sest ikkagi vanemad inimesed ei surfa seal, minu-ealised [---] mitte kõik ei ole kogu aeg telefon käes. Telekas on kõige halvem, ma ei vaata üldse, minu meelset on raadio kõige populaarsem [---] no ja meditsiinitöötajad peaksidki sellest rääkima (6flu_F68).

Nn kolmandate osapoolte puhul muutuvad tähenduse loomes oluliseks arstide, teiste tervishoiutöötajate või meditsiinilise taustaga inimeste arvamused. Uuringule tuginedes ei saa siiski väita, nagu eelistaksid inimesed uskuda pigem tervishoiutöötajat või nn tavalist inimest. Leidus vastajaid, kes eelistaksid kuulda päriselu lugusid, kuid oli ka neid, kes järgiksid meditsiinitaustaga inimeste soovitusi. Oli huvitav täheldada, et vanemaealised ja/või meditsiinilise taustaga inimesed eelistasid oluliste kõneisikutena arste, samas nooremad osalejad eelistasid valdavalt lugeda või kuulda tavainimeste lugusid. Lisadimensioonina tõi mitu vastajat välja vajaduse analüüsida enne lõpliku otsuse kujunemist/kujundamist kogutud informatsiooni iseseisvalt: 
Ma selles mõttes ma olen nagu ka nagu päris palju nagu teadus teadusartikleid läbi töötanud ja ja teadusmaailmas tuleb olla täpselt sama kriitiline kui, kui igal pool ümbritsevas maailmas. Seega ma oleksin nagu, ikkagi ka vaataks kriitiliselt neid andmeid, mis, mis seal [teadusartiklites] kajastatakse (3flu_F27).

Samas võivad isegi allika- või sisukriitilisuse korral tuttavate või tavainimeste kogemused ja ütlused teatud olukorras otsuseid mõjutada:

Ma arvan, et pigem pigem võib-olla teaduslikke fakte (usaldan) rohkem aga selles mõttes siuke nagu teiste patsientide lugusid, siuksed asjad mind tavaliselt jätavad nagu väga külmaks, et et Mai Jõgevalt koges või põdes grippi. No ma ei tea, et noh, jah, loomulikult kui võib-olla räägiks keegi mu tuttav, et oo näe vaata, et mul oli nii raske see juhtum, et näe, ma soovitaks sul ka seda teha. Et ma ikkagi suhtuks võib-olla natukene nagu kriitiliselt, et et kohe ma ei tormaks. Aga noh, kui ta on võib-olla minu-ealine ja kuidagi nagu samastan, samastan ennast temaga, et siis võib-olla tõesti [vaktsineeriksin] (3flu_F27).

Selliselt loodud konstruktsioonid toovad esile, et vahendatud informatsioon või mõju esitab alati väljakutse info vastuvõtjale, mistõttu on vaja mõista loo esitamise analüütilist konteksti. Vastasel juhul jääb esitatud informatsioon kuulujutu tasemel olevaks looks, mis ei suuda esile kutsuda õigustatud tegevusi või tegevuse mõtestamist tähenduslikuna.

Kolmandate osapoolte vahendatud tähenduseloome aspektina on oluline välja tuua ka apteekide mõju, sest alates 2018. aasta oktoobrist on huvilistel olnud võimalik lasta ennast valitud apteekides gripi vastu vaktsineerida. Mõne vastaja hinnangul võib teenuse kättesaadavus mõjutada vaktsineerimisotsust:

Võib olla see asukoha idee oli hea, et pakkuda teenust kergesti kättesaadavates kohtades nagu apteegid. Nii et inimesed ei peaks eriti pingutama (3flu_F27).

Nagu tsitaadist ilmneb, ei ole terviseedenduslikud tegevused (nt vaktsineerimine) enesestmõistetavad ning peavad võistlema arvukate turundus- ja müügitegevustega, mistõttu teenuse muutmine kergemini kättesaadavaks võib suurendada selle kasutatavust. Samal ajal leidus ka vastajaid, kes olid apteegis vaktsineerimisele vastu, kuna ei mõistnud tegevuse seost apteegiga:

See tü̈̈p, kes läheb apteeki vaktsineerima..., ma ei tea, kas see on nagu selline poe taga ôlle pakkumine kuidagi, ma ei oska öelda, ma ei näe seost (9flu_M43). 
Ka mitmed teised vastajad ei näinud, et apteek oleks vaktsineerimiseks sobiv koht, nad arvasid, et see sobiks peamiselt apteegi püsiklientidele.

Oluline nüanss, mida mitmed vastajad välja tõid, oli seotud igapäevatöö ja selle asukohaga, mis võib vaktsineerimas käimise keeruliseks teha. Leiti, et töökohad, aga ka koolid ja lasteaiad võiksid olla kohad, kus koos teadlikkuse tõstmisega saaks pakkuda ka vaktsineerimisvõimalust:

Mina arvan, et see oleks parim variant, kui sul tuleks nagu asi kuskile kohapeale kohale. No see mugavuse teema loomulikult, aga kus ma muidu selle peale tulen? Kui keegi tuleks nagu tööle rääkima asjast, mingisugune väike pooltunnike varem me leiaksime selle. [---] Mina ei eelda, et keegi minu eest midagi maksab, aga see on ju kokkuleppel juba tööandja ja töötaja enda vahel [---]. Samamoodi võiks olla selle saada sama teemaga, et seda pakutaks välja mingi konkreetne periood ja öeldakse, et ma ei tea, mis võimalused on, tullakse kohale või sõidab mingi auto, mingi buss, et kõik saavad sealt bussist läbi käia ja selle vaktsiini ära teha (9flu_M43).

Praktilisest elust lähtuvad barjäärid võivad oluliselt takistada vajalike tervisega seotud tegevuste elluviimist (Lubi et al. 2020), mistõttu tuleks seda kindlasti tervisekaitseliste ennetustegevuste planeerimisel arvesse võtta ning struktuurseid barjääre võimalikult palju vähendada. Samas toob aga antud tsitaat välja veel selle, et ehk on siiani vähe kasutatud tööandjate kui kolmanda osapoolega seotud tähendusloome tasandit, kes saavad panustada gripi (ja ehk ka koroonaviiruse) vastase vaktsineerimise hõlmatusse, aidates muuta teenust kättesaadavaks nii asukoha kui finantsressursi mõttes.

\section{Kokkuvõte}

Haiguste ja vaktsineerimisega seotud tähenduste loomine on keerukas protsess, mis toimub väga erinevatel tasanditel, ja seda suunavad väga erinevat tüüpi mõjutused, selle kujunemine võib olla teadvustamata.

Neoliberaalne lähenemine, mille kohaselt on terviseküsimustes olulisimaks enda seisundi eest vastutajaks inimene, on üles ehitatud pigem ratsionaalsele otsustusele. Selle lähenemise kohaselt tuleb anda inimesele piisav hulk informatsiooni, mille põhjal saab ta teha teadliku ja (biomeditsiinist lähtuvalt) õige otsuse. Nagu aga varasemate ja käesoleva uuringu põhjal ilmneb, tekivad haigustega seotud tähendused valdavalt teistsugustel, sh mitteratsionaalsetel tasanditel. 
Kultuurilisel tasandil loodud tähendus haiguse olemusest ja sellega hakkamasaamise viisid mõjutavad suurel määral seda, milliseid tervisega seotud otsuseid vastu võetakse. Sageli on kultuurilise tasandi tähendused pika aja jooksul inimeste tegutsemisharjumustesse juurdunud, ja seda, miks üht või teist tegevust tehakse või ka tõhusa(ima)ks peetakse (nt hügieen, erinevate ravimtaimede kasutamine jne), ei pea inimesed vajalikuks põhjendada. Kultuurilise tähenduse pikaajalise tekkimise tausta tõttu ei seata sellel tasandil omandatud teadmisi ka kahtluse alla, mis muudab aga uute tegevuste omaksvõtu keerukaks. Viimast mõjutab täiendavalt see, mida meediast või muude kanalite kaudu teada saadakse, ning kui info on vastuoluline, lähtutakse ehteestlaslikust põhimõttest "pigem karta kui kahetseda".

Indiviidi tasandil kujunevaid otsuseid mõjutavad nii kultuurilise tasandi teadmised kui ka see, millised on isiklikud kogemused ning kellena ja kuidas ennast erinevate teemade osas positsioneeritakse. Lisaks neile teguritele võib oluliseks osutuda ka see, milliseid nn kaitsestrateegiaid erinevate otsuste tegemiseks enda jaoks luuakse. Nimetatud asjaolude arvestamine võib olla vaktsineerimisalase tervisekommunikatsiooni kujundamisel üsna oluline, leidmaks viise, mis tõhustaksid vastavasisulise sõnumi vastuvõttu, tõlgendamist ja omandamist. Viimase puhul saab olulise aspektina täiendavalt välja tuua kolmandate osapoolte vahendusel loodud tähendused, mille mõju sõltub aga suurel määral sellest, millised kanalid (sh kõneisikud) on inimestele erinevate teemade puhul olulised.

Kokkuvõtvalt saab uuringule tuginedes välja tuua asjaolu, et uued ja tundmatud olukorrad (nagu koroonaviiruse pandeemia) võivad ajutiselt muuta inimeste arvamusi ja suhtumisi erinevate terviseotsuste, sh vaktsineerimise kui ennetava meetme osas. Pikas perspektiivis on aga olulised just eespool välja toodud tähendusloome tasandid, mistõttu tuleb neile läheneda unikaalsemal viisil (st mitte üksnes ühe haiguse põhiselt) ja arvestada neid erinevate ennetustegevuste planeerimisel, stigmatiseerimata inimeste kujunenud hoiakuid. Samuti on oluline silmas pidada, et vaid hirmul ja muudel negatiivsetel emotsioonidel põhinevad otsustused kaotavad oma veenvuse ja mõju niipea, kui ohuallikas kaob, mistõttu ei kaasne sellistes oludes tehtud otsustega pikaajalisi (ja teadlikke) tervisekäitumisega seotud muutuseid.

\section{Uuringu piirangud}

Sellel uuringul on mõningaid kitsaskohti. Esmalt juba analüüsi peatükis mainitud uuringu elektrooniline läbiviimise vorm, mis aga ei tulenenud meie 
eelistustest, vaid lähtus riigis valitsenud eriolukorrast ja sellega kaasnenud piirangutest. Teiseks valimi suurus ja koosseis, mida ei saa kindlasti pidada esinduslikuks ja seetõttu pole ka saadud tulemused üldistatavad suuremale populatsioonile. Samas on oluline asjaolu, et andmekogumisel lähtusime eespool mainitud kvalitatiivsetele uuringutele omasele andmete küllastatuse põhimõttest, mistõttu võimaldab kogutud andmete hulk teha antud uuringu raames järeldusi. Ka valimi suurus ning kasutusel olnud mugavus- ja lumepallivalimi moodustamise meetod tulenesid teatud määral riigis kehtinud eriolukorrast. Uuringu meetodina oli kasutusel poolstruktureeritud intervjuu, mistõttu ei too me artiklis välja ka intervjuukava, sest vastajatele võimaldati kava küsimustest eemale kaldumist määral, mis võimaldas siiski teemas püsimist. See meetod võimaldas meil saada arvamusi ka selliste nüansside kohta, mida me uurijatena ei osanud eelnevalt välja tuua, kuid mis on teema käsitlemisel oluline. Oluline on see, et alates andmete kogumisest on vaktsineerimise teema, eriti koroonatõve kontekstis, saavutanud uued mõõtmed ning kindlasti tuleks edaspidi uurida teemat nii toodud sihtrühma, kui ka teiste sihtrühmade (näiteks tervishoiutöötajad) hulgas. Kuna kevadel need teemad veel nii esile ei olnud tulnud, siis antud artikkel neid teemaid ei käsitle. Vaatamata toodud piirangutele oleme siiski seisukohal, et saadud andmed annavad viirusnakkushaigustega ja nendega seotud vaktsineerimise tähendusloome osas olulist esmast teavet, mis aitab mõista terviskäitumist puudutavate otsuste võimalikke täiendavaid tasandeid lisaks ratsionaalsele informeerituse ja teadlikkusega seotud lähenemistele.

\section{Tänusõnad}

Artikkel on seotud Tallinna Tervishoiu Kõrgkooli omafinantseeritud projektiga \#30 “Tervishoiutöötajate ja elanikkonna võimalused, vajadused ja hoiakud seoses gripivastase vaktsineerimisega ja teenuse kättesaadavus".

\section{Kommentaar}

1 Siin ja edaspidi on terminid autorite poolt välja pakutud ingliskeelsete terminite eestikeelsed tõlked ja mugandused, kuna ametlikud terminid Rahvatervise raamatukogus puuduvad. 


\section{Kirjandus}

Beauchamp, Tom Lamar 2015. The "Four Principles" Approach to Health Care Ethics. Ashcroft, Richard Edmund \& Dawson, Angus \& Draper, Heather \& McMillan, John (toim). Principles of Health Care Ethics. Chichester: John Wiley \& Sons Ltd, lk 3-10 (doi: 10.1002/9780470510544.ch1).

Buonaccorso, Loredana \& Martucci, Gianfranco \& Miccinesi, Guido \& Maruelli, Alice \& Ripamonti, Carla 2019. Construction of New Personal Meanings by Cancer Patients: A Qualitative Analysis in an Italian Patient Population. Support Care Cancer 27 (5), lk 1911-1918 (doi: 10.1007/s00520-018-4444-2).

Charmaz, Kathy 2002. The Self as Habit: The Reconstruction of Self in Chronic Illness. The Occupational Therapy Journal of Research 22 (Supplement), lk 31-41 (doi: 10.1177/15394492020220S105).

Charmaz, Kathy 2006. Measuring Pursuits, Marking Self: Meaning Construction in Chronic Illness. International Journal of Qualitative Studies on Health and Well-Being 1 (1), lk 27-37 (doi: 10.1080/17482620500534488).

Conrad, Peter \& Barker, Kristin K. 2010. The Social Construction of Illness: Key Insights and Policy Implications. Journal of Health and Social Behavior 51 (1_suppl), lk 67-79 (doi: 10.1177/0022146510383495).

Dror, Amiel A. \& Eisenbach, Netanel \& Taiber, Shahar \& Morozov, Nicole G. \& Mizrachi, Matti \& Zigron, Asaf \& Srouji, Samer \& Sela, Eyal 2020. Vaccine Hesitancy: The next Challenge in the Fight against COVID-19. European Journal of Epidemiology 35 (8), lk 775-779.

Dubé, Eve \& Gagnon, Dominique \& Nickels, Emily \& Jeram, Stanley \& Schuster, Melanie 2014. Mapping Vaccine Hesitancy-Country-Specific Characteristics of a Global Phenomenon. Vaccine 32 (49), lk 6649-6654 (doi: 10.1016/j.vaccine.2014.09.039).

Dubé, Eve \& Vivion, Maryline \& MacDonald, Noni E. 2014. Vaccine Hesitancy, Vaccine Refusal and the Anti-Vaccine Movement: Influence, Impact and Implications. Expert Review of Vaccines 14 (1), lk 99-117 (doi: 10.1586/14760584.2015.964212).

Dutta, Mohan J. 2015. Neoliberal Health Organizing: Communication, Meaning and Politics. Oxon: Routledge.

Eisenberg, Leon 1977. Disease and Illness Distinctions between Professional and Popular Ideas of Sickness. Culture, Medicine and Psychiatry 1, lk 9-23 (doi: 10.1007/BF00114808).

EVV 2020 = Valitsus kuulutas Eestis välja eriolukorra 1. maini. Eesti Vabariigi Valitsus. kriis.ee. Uudised 12. märts (https://www.kriis.ee/et/uudised/valitsus-kuulutas-eestisvalja-eriolukorra-1-maini - 9. märts 2021).

Govaert, Thomas ME \& van Essen, Gerrit Adrianus 2003. Influenza. Jones. Roger \& Britten, Nicky \& Culpepper, Larry \& Gass, David \& Grol, Richard \& Mant, David \& Silagy, Chris (toim). Oxford Textbook of Primary Care. Oxford: Oxford University Press, lk 1265-1270. 
Hagood, E. Allison \& Herlihy, Stacy Mintzer 2013. Addressing Heterogeneous Parental Concerns about Vaccination with a Multiple-Source Model: A Parent and Educator Perspective. Human Vaccines and Immunotherapeutics 9 (8), lk 1790-1794 (doi: 10.4161/ hv.24888).

Hall, Kevin \& Wolf, Meike 2019. Whose Crisis? Pandemic Flu, 'Communication Disasters' and the Struggle for Hegemony. Health (United Kingdom), lk 1-17 (doi: 10.1177/1363459319886112).

Harrison, Emily A. \& Wu, Julia W. 2020. Vaccine Confidence in the Time of COVID-19. European Journal of Epidemiology 35 (4), lk 325-330 (doi: 10.1007/s10654-020-00634-3).

Hennoste, Tiit 2000. Sissejuhatus suulisesse eesti keelde: lausung suulises kõnes I. Akadeemia 10, lk 2223-2254.

Jorgensen, Pernille \& Mereckiene, Jolita \& Cotter, Suzanne \& Johansen, Kari \& Tsolova, Svetla \& Brown, Caroline 2018. How Close Are Countries of the WHO European Region to Achieving the Goal of Vaccinating 75\% of Key Risk Groups against Influenza? Results from National Surveys on Seasonal Influenza Vaccination Programmes, 2008/2009 to 2014/2015. Vaccine 36 (4), lk 442-452 (doi: 10.1016/j.vaccine.2017.12.019).

Lubi, Kadi 2019. The adaptation of everyday practices in the adoption of chronic illness. Health: An Interdisciplinary Journal for the Social Study of Health, Illness and Medicine 23 (3), lk 325-343 (doi: 10.1177/1363459317742263).

Lubi, Kadi \& Koor, Marilyn \& Nool, Irma \& Tupits, Mare \& Mets-Oja, Silja \& Kõiv, Taisi 2020. 50-69aastaste naiste rinnavähi sõeluuringul mitteosalemist mõjutavad põhjused Eestis. Eesti Arst 99 (1), lk 139-146.

Lupton, Deborah 2012. Medicine as Culture. Illness, Disease and the Body. 3rd ed. London: SAGE Publications Ltd.

Mik-Meyer, Nanna \& Roelsgaard Obling, Anne 2012. The Negotiation of the Sick Role: General Practitioners' Classification of Patients with Medically Unexplained Symptoms. Sociology of Health and Illness 34 (7), lk 1025-1038 (doi: 10.1111/j.14679566.2011.01448.x).

Morden, Andrew \& Jinks, Clare \& Ong, Bie Nio 2017. Temporally Divergent Significant Meanings, Biographical Disruption and Self-Management for Chronic Joint Pain. Health: An Interdisciplinary Journal for the Social Study of Health 21 (4), lk 357-374 (doi: 10.1177/1363459315600773).

Nettleton, Sarah 2013. The Sociology of Health and Illness. 3rd edition. Cambridge: Polity Press.

OKE 2021 = Koroonakaart. Open Knowledge Estonia (https://koroonakaart.ee/et/faq 8. märts 2021).

Peretti-Watel, Patrick \& Larson, Heidi J. \& Ward, Jeremy K. \& Schulz, William S. \& Verger, Pierre 2015. Vaccine Hesitancy: Clarifying a Theoretical Framework for an Ambiguous Notion. PLoS Currents 7 (OUTBREAKS) (doi: 10.1371/currents.outbreaks.6844c80ff9 f5b273f34c91f71b7fc289). 
Petrova, Velislava N. \& Russell, Colin A. 2018. The Evolution of Seasonal Influenza Viruses. Nature Reviews Microbiology 16 (1), lk 47-60 (doi: 10.1038/nrmicro.2017.118).

Raal, Ain \& Arak, Elmar 2006. Eesti etnofarmakognoosia elujõust kummelite näitel. Mäetagused 34, lk 149-184 (doi: 10.7592/MT2006.34.kummel).

Robert, J. \& Detournay, B. \& Levant, M. C. \& Uhart, M. \& Gourmelen, J. \& Cohen, J. M.2019. Flu Vaccine Coverage for Recommended Populations in France. Medecine et Maladies Infectieuses, lk 8-13 (doi: 10.1016/j.medmal.2019.12.004).

Rossman, Jeremy S. \& Lamb, Robert A. 2011. Influenza Virus Assembly and Budding. Virology 411 (2), lk 229-236 (doi: 10.1016/j.virol.2010.12.003).

RT 2019 = Isikuandmete kaitse seadus. Riigi Teataja (https://www.riigiteataja.ee/ akt/104012019011 - 9. märts 2021).

Schatzki, Theodore 2013. The Edge of Change: On the Emergence, Persistence, and Dissolution of Practices. Shove, Elizabeth \& Spurling, Nicola (toim). Sustainable Practices: Social Theory and Climate Change. Oxon: Routledge, lk 31-46.

Schmid, Philipp \& Rauber, Dorothee \& Betsch, Cornelia \& Lidolt, Gianni \& Denker, Marie Luisa 2017. Barriers of Influenza Vaccination Intention and Behavior - A Systematic Review of Influenza Vaccine Hesitancy, 2005-2016. Plos One 12 (1): e0170550 (doi: 10.1371/journal.pone.0170550).

Schuster, Melanie \& Eskola, Juhani \& Duclos, Philippe \& Liang, Xiaofeng \& Chaudhuri, Mohuya \& Dube, Evé \& Gellin, Bruce \& Goldstein, Susan \& Larson, Heidi \& MacDonald, Noni \& Manzo, Mahamane Laouali \& Reingold, Arthur \& Tshering, Kinzang \& Zhou, Yuqing \& Guirguis, Sherine \& Hickler, Ben 2015. Review of Vaccine Hesitancy: Rationale, Remit and Methods. Vaccine 33 (34), lk 4157-4160 (doi: 10.1016/j.vaccine.2015.04.035).

Sobo, Elisa J. 2016. Theorizing (Vaccine) Refusal: Through the Looking Glass. Cultural Anthropology 31 (3), lk 342-350 (doi: 10.14506/ca31.3.04).

Tervise Arengu Instituut 2020. Gripivastane vaktsineerimine vanuserühmade lõikes. Tervisestatistika ja terviseuuringute andmebaas (https://www.tai.ee/et/terviseandmed/ tervisestatistika-ja-uuringute-andmebaas/uuendused/4520-andmed-nakkushaigustessehaigestumise-ja-vaktsineerimise-kohta-2018 - 22. märts 2021).

Terviseamet 2019 = Gripihooaja kokkuvõte 2018/2019.Terviseamet (https://www. terviseamet.ee/sites/default/files/Nakkushaigused/Haigestumine/nakkush_statistika/ gripoihooaja_kokkuvote_2018.pdf - 8. märts 2021).

Toombs, S. Kay. 1992. The Meaning of Illness: A Phenomenological Account of the Different Perspectives of Physician and Patient. Dordrecht: Springer-Science+Business Media, B.V.

Turu-uuringute AS 2020 = Eesti inimeste ohutunnetus koroonaviiruse leviku suhtes on võrreldes juuliga kahekordistunud. Turu-uuringute $A S$ (https://turu-uuringute. eu/eesti-inimeste-ohutunnetus-koroonaviiruse-leviku-suhtes-on-vorreldes-juuligakahekordistunud/ - 11. märts 2021).

Uibu, Marko \& Vihalemm, Triin 2017. Tervisepüüdlused ühiskonna polariseerijana? Vihalemm, Peeter \& Lauristin, Marju \& Kalmus, Veronika \& Vihalemm, Triin (toim). 
Eesti ühiskond kiirenevas ajas. Uuringu "Mina.Maailm.Meedia" 2002-2014 tulemused. Tartu: University of Tartu Press, lk 343-362.

WHO2020a. Coronavirus. World Health Organization (https://www.who.int/healthtopics/coronavirus\#tab=tab_1 - 11. märts 2021).

WHO 2020b. Influenza Vaccination Coverage and Effectiveness. World Health Organization (https://www.euro.who.int/en/health-topics/communicable-diseases/influenza/ vaccination/influenza-vaccination-coverage-and-effectiveness - 11. märts 2021).

WHO 2020c. WHO Director-General's Opening Remarks at the Media Briefing on COVID-19 - 11 March 2020. World Health Organization (https://www.who.int/dg/ speeches/detail/who-director-general-s-opening-remarks-at-the-media-briefing-on-covid19---11-march-2020 - 11. märts 2021).

WMA 2013. WMA Declaration of Helsinki - Ethical Principles for Medical Research Involving Human Subjects. World Medical Assotiation 9th July 2018. (https://www.wma. net/policies-post/wma-declaration-of-helsinki-ethical-principles-for-medical-researchinvolving-human-subjects/ - 11. märts 2021).

\section{Summary}

\section{"Death is the only thing that scares": The construction of meaning about vaccination decision on the example of influenza and coronavirus}

\section{Kadi Lubi}

Associate Professor

Health Education Centre, Tallinn Health Care College

kadi.lubi@ttk.ee

\section{Eliisa Metsoja}

Chief Specialist of Influenza Centre

Health Board of the Republic of Estonia

Eliisa.Metsoja@gmail.com

\section{Kaie Eha}

Head of the Pharmaceutical Curriculum in English

Medical Technology Education Centre, Tallinn Health Care College

Kaie.Eha@ttk.ee

Silja Mets-Oja

Head of the Health Education Centre, Tallinn Health Care College

Silja.Mets-Oja@ttk.ee

\section{Lilian Ruuben}

Head of the Medical Technology Education Centre, Tallinn Health Care College Lilian.Ruuben@ttk.ee 
Keywords: construction of illness meaning, coronavirus (COVID-19), influenza, vaccination, vaccine hesitancy

Although relatively easy to overcome for young and healthy individuals, seasonal influenza is a disease with considerable health, social, and economic consequences for society, especially for higher-risk groups. Even though vaccination against influenza is the most effective tool to prevent it, vaccination rates remain rather low. Together with the promotion of neoliberal individual responsibility over one's health, vaccine hesitancy - a complex phenomenon indicating the lower uptake of vaccines compared to the accessibility of information and services - has risen among societies. In previous research, several barriers - for example, psychological, physical, contextual, and sociodemographic - have been identified as preventing influenza vaccine uptake among risk groups. We approach the topic by using the social constructionist theory regarding the meaning construction of illnesses on cultural, individual, and third-party level. The findings outline the importance of meaning construction on all these levels. It appears that culturally influenza has been seen as an inevitable infectious disease related to the northern climate. Due to that, influenza is not considered as a life-threatening disease that would need preventive actions, except some basic hygiene or usage of folk medicine tools (e.g., ginger and garlic). On an individual level, the meaning construction is based on individual experiences, both with the illness and the vaccine - in the case of negative experiences with vaccine, the perception of something useless or even harmful develops. In addition, it appears that people create their own strategies to rationalize rejection of vaccination for themselves. These involve considerations about belonging to the risk group or the possibility to manage daily activities in non-risky manner even when belonging to the risk group.

On the third-party level, participants saw the potential of pharmacies to alleviate practical constraints (e.g., tight schedule, daily occupation, etc.). Different media channels are also important in mediating vaccination-related information, but the rationalization and selection of the channels vary widely.

The context of the coronavirus changed the vaccination-related perception temporarily for a short term, indicating that fear-based special occasions do not entail a long-term shift in health behaviour as the development of health-related decisions and behaviour is also long-term.

Kadi Lubi (PhD, MA) on Tallinna Tervishoiu Kõrgkooli tervishariduse keskuse dotsent, kelle uurimishuvi on seotud tervise ja haigusega seotud arusaamade, hoiakute ning tervisealaste otsuste kujunemisega. Senised uurimistööd on käsitlenud nimetatud teemasid nii tervisekommunikatsiooni, meditsiinisotsioloogia kui meditsiiniantropoloogia valdkondades.

Kadi Lubi $(\mathrm{PhD})$ is Associate Professor at the Health Education Centre of Tallinn Health Care College. Her research interests include concepts of and attitudes to health and diseases as well as health-related decisions. Her research 
has covered these topics in the spheres of health communication, medical sociology, and medical anthropology.

kadi.lubi@ttk.ee

Eliisa Metsoja (BA) on Tallinna Tervishoiu Kõrgkooli tervisedenduse õppekava vilistlane ja Terviseameti gripikeskuse peaspetsialist, kes uuris oma lõputöös seda, millised on end gripi vastu mittevaktsineerinud inimeste arvamused ja arusaamad gripist ja sellega seotud vaktsineerimisest.

Eliisa Metsoja (BA) has a BA in health education from Tallinn Health Care College and she works as Chief Specialist of Influenza Centre at the Health Board of the Republic of Estonia. Her thesis discussed the opinions of unvaccinated people about influenza and vaccination.

Eliisa.Metsoja@gmail.com

Kaie Eha (MSc) on Tallinna Tervishoiu Kõrgkooli meditsiinitehnilise hariduse keskuses farmatseudi ingliskeelse õppekava juht, kelle peamised uurimishuvid on seotud ravimtaimede efektiivsuse ja ohutusega ning sotsiaalfarmaatsia valdkonnaga, eeskätt farmatseudi kutsekuvandiga.

Kaie Eha (MSc) is Head of the Pharmaceutical Curriculum in English at the Medical Technology Education Centre of Tallinn Health Care College. Her main research interests are related to the efficiency and safety of herbs as well as the sphere of social pharmacy.

Kaie.Eha@ttk.ee

Silja Mets-Oja (MA) on Tallinna Tervishoiu Kõrgkooli tervishariduse keskuse juht, kelle uurimishuvid on seotud tervishoiu korraldamisega erinevatel ühiskondlikel tasanditel.

Silja Mets-Oja (MA) is Head of the Health Education Centre of Tallinn Health Care College, whose research interests cover health care management at different social levels.

Silja.Mets-Oja@ttk.ee

Lilian Ruuben (MSc) Tallinna Tervishoiu Kõrgkooli meditsiinitehnilise hariduse keskuse juht, kelle uurimishuvi on seotud toidulisandite kvaliteedi ja toimega ning apteegiteenuse arendamisega seal pakutavate terviseteenuste kontekstis. 
Lilian Ruuben (MSc) is Head of the Medical Technology Education Centre of Tallinn Health Care College, whose research interests are related to the quality and impact of food additives as well as the development of pharmacists' services in the context of health services.

Lilian.Ruuben@ttk.ee 